\title{
Commentary: Single- versus multidose cardioplegia: Could 15 minutes save your patient?
}

Niv Ad, MD

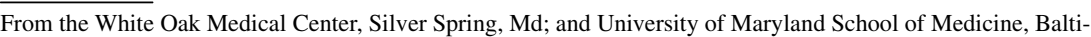
more, Md.

Disclosures: Dr Ad is a consultant for Medtronic, a member of the speaker's bureau for AtriCure, a proctor and member of the speaker's bureau for LivaNova, on the advisory board for Nido Surgical, and co-owner for Left Atrial Appendage Occlusion, LLC.

Received for publication Aug 14, 2019; revisions received Aug 14, 2019; accepted for publication Aug 14, 2019; available ahead of print Sept 20, 2019

Address for reprints: Niv Ad, MD, Division of Cardiac Surgery, University of Maryland School of Medicine, 110

S Paca St, 7th Floor, Baltimore, MD 21201 (E-mail: nivadmd14@gmail.com).

J Thorac Cardiovasc Surg 2020;160:1205-6

$0022-5223 / \$ 36.00$

Copyright (C) 2019 Published by Elsevier Inc. on behalf of The American Association for Thoracic Surgery https://doi.org/10.1016/j.jtcvs.2019.08.081
}

In this issue of The Journal of Thoracic and Cardiovascular Surgery, Dr Ivancarmine Gambardella and colleagues share with us their results of an excellent meta-analysis comparing single-dose cardioplegia (del Nido [DN] cardioplegia and histidine-tryptophan-ketoglutarate [HTK] cardioplegia) with standard multidose cardioplegia. ${ }^{1}$ The primary end point of the study was in-hospital or 30-day mortality whereas the secondary end point focused on cardiopulmonary bypass time, cross-clamp time, fibrillatory reperfusion, myocardial infarct, and elevation of cardiac enzymes (creatine kinase myocardial band and troponin I). The analysis was on the basis of 10 randomized controlled trials and 13 propensity matched analyses with more than 5000 patients. The authors adhered to the Preferred Reporting Items for Systematic Reviews and Meta-Analyses guidelines ${ }^{2}$ and provided us with a very reliable document.

The question of what method of myocardial preservation is the best one is somewhat a hot topic lately and this report, as others before, is set to answer 2 simple questions:

(1) What is the best myocardial protection?

(2) Which method is least cumbersome to the operative flow?

All methods of cardioplegia delivery were shown to be similar when it comes to operative mortality. However, the study revealed that only DN cardioplegia was associated with shorter ischemic time, lower postoperative peak enzyme levels, and reduced reperfusion ventricular fibrillation. This effect was not captured for HTK cardioplegia.

The current analysis is reassuring in that we probably do not harm the average patient coming to heart surgery by using any of the established myocardial preservation methods. But this type of study can only rely on the already published literature that leaves us with quite a few unanswered questions. ${ }^{3,4}$

When reading this excellent analysis, I believe that surgeons should also consider the existing gaps in the

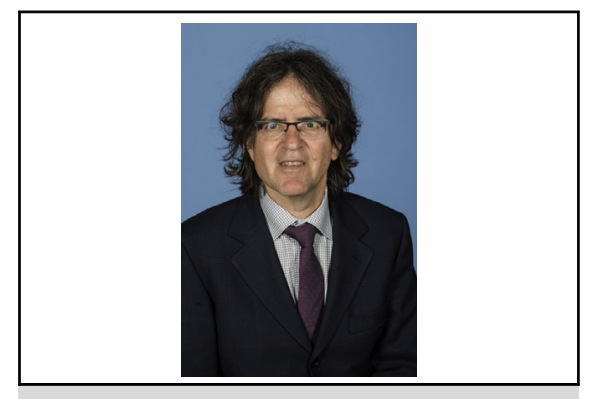

Niv Ad, MD

Central Message

The current meta-analysis reconfirmed that single-dose cardioplegia is safe when dealing with straightforward cases.

See Article page 1195 .

evidence that might be very important in their decision and the way they choose to protect the heart:

1. What is the best approach for patients with complex pathology that will require multiple valve procedures, great vessels intervention, redo procedures, or lengthy concomitant procedures?

2. How should preoperative left ventricular or right ventricular dysfunction be approached when deciding the type of cardioplegia?

3. What would be the best cardioplegia strategy and type for a second or third cross-clamp run, if the initial method was the use of DN cardioplegia?

4. What is the effect of the different myocardial preservation methods beyond the first 24 to 48 hours postoperatively? Myocardial enzymes levels, subendocardial damage, and echocardiography findings would be important to examine.

5. How does nonwhole blood cardioplegia influence the rate of blood transfusion?

These questions should probably be answered in the near future and the appropriate studies should be designed.

In summary, the current meta-analysis reconfirmed what was suggested previously that DN and HTK cardioplegia are safe when dealing with straightforward cases. It is also clear that at least in the case of DN cardioplegia the cross-clamp time is shorter, but both alternatives probably offer better surgical flow, especially in cases of limited access and minimally invasive procedures. 


\section{References}

1. Gambardella I, Gaudino MFL, Antoniou GA, Rahouma M, Worku B, Tranbaugh RF, et al. Single- versus multidose cardioplegia in adult cardiac surgery patients: a meta-analysis. J Thorac Cardiovasc Surg. 2020;160:1195-202.e12.

2. Liberati A, Altman DG, Tetzlaff J, Mulrow C, Gøtzsche PC, Ioannidis JP, et al. The PRISMA statement for reporting systematic reviews and meta-analyses of studies that evaluate healthcare interventions: explanation and elaboration. BMJ. 2009;339:b2700.
3. Ad N, Holmes SD, Massimiano PS, Rongione AJ, Fornaresio LM, Fitzgerald D The use of del Nido cardioplegia in adult cardiac surgery: a prospective randomized trial. J Thorac Cardiovasc Surg. 2018;155:1011-8.

4. An KR, Rahman IA, Tam DY, Ad N, Verma S, Fremes SE, et al. A systematic review and meta-analysis of del Nido versus conventional cardioplegia in adult cardiac surgery. Innovations (Phila). July 26, 2019 [Epub ahead of print]. 